
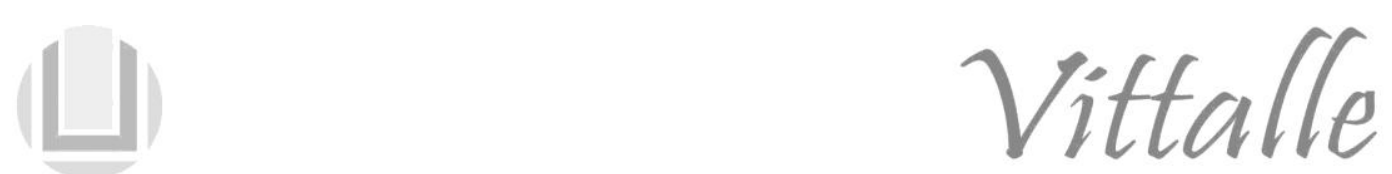

\title{
RESENHA \\ SAAD, Glaucia de Azevedo; LÉDA, Paulo Henrique de Oliveira; SÁ, Ivone Manzali de; SEIXLACK, Antonio Carlos de Carvalho. Fitoterapia Contemporânea: Tradição e Ciência na Clínica Prática. $2^{\mathrm{a}}$ edição. Rio de Janeiro: Guanabara Koogan, 2016.
}

\author{
Leopoldo Clemente Baratto*
}

Faculdade de Farmácia, Universidade Federal do Rio de Janeiro, Rio de Janeiro, RJ, Brasil

\author{
Histórico do Artigo \\ Recebido em: \\ $18 / 12 / 2017$ \\ Aceito em: \\ $25 / 02 / 2018$
}

\author{
RESUMO \\ Resenha do livro SAAD, Glaucia de Azevedo; LÉDA, Paulo Henrique de Oliveira; SÁ, Ivone \\ Manzali de; SEIXLACK, Antonio Carlos de Carvalho. Fitoterapia Contemporânea: Tradição e \\ Ciência na Clínica Prática. 2a edição. Rio de Janeiro: Guanabara Koogan, 2016.
}

A obra intitulada "Fitoterapia Contemporânea: Tradição e Ciência na Clínica Prática" foi elaborada pelos autores Glaucia de Azevedo Saad, médica especialista em acupuntura e fitoterapia; Paulo Henrique de Oliveira Léda, farmacêutico, Mestre em Ciências Biológicas (Farmacologia e Terapêutica Experimental) pela UFRJ; Ivone Manzali de Sá, farmacêutica, Doutora em História das Ciências e da Saúde pela Casa de Oswaldo Cruz (Fiocruz); e Antonio Carlos de Carvalho Seixlack, médico especialista em acupuntura e fitoterapia. O livro, em sua segunda edição, contém 441 páginas, dividido em oito capítulos, contendo figuras e ilustrações coloridas. Os capítulos são os seguintes: 1 - Histórico da Fitoterapia; 2 - Plantas Medicinais nos Sistemas Médicos; 3 - Noções de Botânica; 4 - Fitoquímica e Farmacologia Aplicadas; 5 - Farmacotécnica; 6 - Clínica Médica/Diagnóstico e Prescrição; 7 - Monografia das Plantas Medicinais; e 8 - Casos Clínicos.

No primeiro capítulo (Pág. 2), é apresentado um panorama histórico da fitoterapia, desde os primórdios da humanidade até os dias atuais, passando pelos sistemas de medicina tradicional chinês e indiano, apresentando as contribuições dos grandes nomes da antiguidade grega, como Pitágoras, Hipócrates, Plínio, Theofrastus e Galeno, até a Idade Média e a Renascença. O segundo capítulo (Pág. 7) apresenta, de uma forma geral, os conhecimentos a respeito dos sistemas de medicina greco-romana (teoria dos humores), ayurveda e chinesa. No terceiro capítulo (Pág. 13), o leitor tem contato com noções de botânica, trazendo importantes conceitos a respeito da classificação dos vegetais, regras de nomenclatura botânica e órgãos das plantas. Esse capítulo é de suma importância, principalmente a profissionais com pouca base teórica sobre terminologias botânicas, além de ser um guia para quem já trabalha na área. O capítulo 4 (Pág. 21) aborda fitoquímica e farmacologia aplicadas, mostrando as classes de princípios ativos sintetizados pelas plantas, bem como seus efeitos farmacológicos e mecanismos de ação

\footnotetext{
*Autor correspondente: leopoldo.ufrj@gmail.com (L. C. Baratto)
} 
no organismo. Com uma linguagem bastante clara, profissionais da área da saúde, que não são farmacêuticos e poderiam ter mais dificuldade na compreensão e no estudo dos metabólitos secundários, como médicos, nutricionistas, enfermeiros etc, podem ter acesso a um material rico em informações que não exige um conhecimento aprofundado em Química Orgânica ou Farmacognosia. Uma outra parte interessante deste capítulo é o tópico sobre farmacocinética aplicada às drogas vegetais e grupos fitoquímicos, dificilmente encontrados na literatura pela falta de estudos científicos, abordando aspectos relacionados à absorção, à distribuição, à metabolização e à eliminação de ginkgo, hipérico, salgueiro, antraquinonas, isoflavonas e taninos. O capítulo 5 (Pág. 51) aborda aspectos farmacotécnicos como processos de secagem e estabilização de drogas vegetais, formas farmacêuticas e exemplos de prescrição dessas formas. O controle de qualidade também é abordado. O capítulo 6 (Pág. 61) aborda aspectos da clínica médica: diagnóstico e prescrição, trazendo elementos de anamnese, exame físico, diagnóstico, prognóstico e tratamento. O tópico "diagnóstico e prescrição" separa por sistemas corporais as doenças e exemplos de prescrição para cada caso. É importante salientar que os autores abordam o diagnóstico sob a ótica da Medicina Tradicional Chinesa, pois trazem para a avaliação sinais e sintomas relacionados aos fatores patogênicos externos (frio, calor, secura, umidade e fleuma) e, também, relacionam aos padrões sindrômicos de excesso, deficiência e estagnação. Ainda sob a ótica da Medicina Tradicional Chinesa, é abordada a anamnese, por meio da avaliação do pulso da artéria radial e língua, inclusive com fotos ilustrativas para melhor entendimento.

O capítulo 7 (Pág. 99) elenca as monografias de diversas espécies vegetais com propriedades medicinais. No início do capítulo, as plantas são separadas por sistemas, o que facilita a consulta do leitor na procura por plantas relacionadas às enfermidades de interesse. A partir da página 103, o capítulo traz as monografias propriamente ditas. Ao todo, são 96 monografias de plantas medicinais. As monografias estão elencadas por ordem alfabética do nome popular da planta e cada uma traz as seguintes informações: nome botânico, nome farmacêutico, família, partes utilizadas, propriedades organolépticas, origem, histórico, principais componentes químicos, atividades farmacológicas, indicações e usos principais, uso etnomedicinal, posologia, extratos e produtos disponíveis no mercado brasileiro, contraindicações, precauções, toxicidade e referências bibliográficas. Das 96 plantas medicinais, apenas 31 são espécies nativas ou encontradas em território brasileiro. E, de todas as espécies elencadas, 38 possuem monografia na Farmacopeia Brasileira, $5^{\text {a }}$ edição. Em 2017, a Farmacopeia Brasileira passou a contar com um total de 147 monografias de plantas medicinais, a partir da publicação da RDC 167/2017, que aprovou o segundo suplemento farmacopeico. Nessa nova versão, a Farmacopeia volta a trazer monografias de plantas que constavam em edições mais antigas, resgatando a importância dessas drogas vegetais, a exemplo da agoniada (Himathanthus bracteatus, Apocynaceae), presente na primeira Farmacopeia Brasileira (1929), porém suprimida das edições posteriores. As monografias do livro estão alinhadas, de um modo geral, com as plantas clássicas estudadas na Farmacognosia - a área das Ciências Farmacêuticas que estuda os princípios ativos de origem natural sob aspectos botânicos, químicos e farmacológicos. Observa-se que algumas espécies não foram incluídas, embora tradicionalmente importantes, como, por exemplo, ruibarbo (Rheum officinale, R. palmatum, Polygonaceae), cáscara-sagrada (Rhamnus purshiana, Rhamnaceae) e frângula (Rhamnus frangula, Rhamnaceae), espécies ricas em antraquinonas com propriedades laxativas; ginseng (Panax ginseng, Araliaceae) e polígala (Polygala senega, Polygalaceae), ricas em saponinas; assim como não são mencionados erva-doce (Pimpinella anisum, Apiaceae), anis estrelado (Illicium verum, Schisandraceae), benjoim (Styrax benzoin, Styraceae), bálsamos do Peru e Tolú 
(Myroxylon balsamum, Fabaceae), dedaleira (Digitalis spp., Plantaginaceae), quina (Cinchona spp., Rubiaceae) etc. Outras espécies que estão em alta no momento, tais como hibisco (Hibiscus sabdariffa, Malvaceae), também não são encontradas entre as monografias, mas, por outro lado, o livro inclui o cranberry (Vaccinium oxycoccos, Ericaceae), igualmente rico em antocianinas. A não inclusão de algumas espécies clássicas é também positiva, se levarmos em consideração o desuso de várias dessas plantas, como dedaleira, rauvolfia (Rauvolfia serpentina, Apoycnaceae) e quina, mostrando que a Fitoterapia e a Farmacognosia são áreas dinâmicas, que acompanham, também, uma mudança, conforme o conhecimento científico é produzido e o acesso ao material vegetal é disponível. Por outro lado, espécies como cáscara-sagrada, ginseng, erva-doce e bálsamo de Tolú são encontradas no mercado varejista sob a forma de medicamentos e suplementos alimentares e, por isso, seria de extremo valor a presença de suas respectivas monografias nesta obra, já que a mesma é voltada para prescritores. O ponto alto das monografias é a inclusão de plantas brasileiras, que, apesar de pouco estudadas, possuem grande importância na medicina popular, entre elas, a já mencionada agoniada, arnica do campo (Solidago chilensis, Asteraceae), embaúba (Cecropia spp., Cecropiaceae), erva-baleeira (Varronia curassavica, Boraginaceae), chambá (Justicia pectoralis, Acanthaceae), carqueja (Baccharis trimera, Asteraceae), mulungu (Erythrina verna, Fabaceae), andiroba (Carapa guianensis, Meliaceae) e copaíba (Copaifera spp., Fabaceae), entre outras.

O último capítulo do livro (Cap. 8; pág. 419) traz 28 casos clínicos, separados por sistemas fisiológicos ou propriedades (Sistemas Nervoso, Digestório, Respiratório, Cardiovascular, Geniturinário, Tegumentar, Musculoesquelético e Endócrino; Tônicas e Imunoestimulante). Em função do caráter prático e didático da obra, o capítulo aborda exemplos cotidianos na clínica, com os quais os profissionais da saúde prescritores de fitoterápicos poderão se deparar. Cada caso clínico tem uma resposta, a qual é exemplificada com fórmulas fitoterápicas, cuja maioria é baseada no uso de associações, comum à prescrição fitoterápica. O objetivo desse capítulo, segundo os próprios autores, é que, por meio de cada caso clínico, seja concluído o diagnóstico clínico e sejam identificados os conceitos tradicionais predominantes, assim como elaboradas as estratégias terapêuticas.

A leitura dessa obra é altamente recomendada para todos aqueles profissionais que atuam na área da Fitoterapia e Medicina Tradicional Chinesa, com uma linguagem bastante acessível para farmacêuticos, médicos, nutricionistas, biólogos, enfermeiros, entre outros. O livro é um excelente material de consulta para prescritores de fitoterápicos e plantas medicinais, principalmente pelo fato de contemplar monografias de plantas medicinais nativas brasileiras e farmacopeicas. 
EDITORA E GRÁFICA DA FURG

CAMPUS CARREIROS

CEP 96203900

editora@furg.br 